\title{
Lessons from Japan: Promoting Underutilized Food Crops Through Tourism
}

\author{
Rachel Thomas Tharmabalan
}

\author{
School of Ethnic Studies, Level 4, Administration building, Kolej Keris Mas, Universiti Kebangsaan Malaysia, \\ 43600 Bangi, Selangor \\ rachthomas777@gmail.com \\ TEL.: +60174172171
}

Received: 28 June 2019; Published online: 18 October 2021

\begin{abstract}
For the first time in the XXI century, the number of people suffering from obesity worldwide surpassed the number of undernourished people. For many developing countries, this presented a so-called "double burden" of coping for over- and under-nourishment. At a rate of more than $50 \%$ of the population in Malaysia being either overweight or obese, the country is facing the most severe dietary crisis in East Asia. Often recognized as one of the healthiest populations worldwide and having a blue zone, Japan has managed to set a yardstick for countries around Asia. Hence the purpose of this study was to uncover the capacity for contribution and successful integration of traditional vegetables into Japanese daily food practices. Semi structured interviews were conducted together with participatant observation with key informants to help understand the role of women in preserving and safeguarding traditional vegetables also known as 'sansai' in terms of farming and food preparation. In order to solve the unhealthy eating patterns among Malaysians, it is timely to start appreciating the contributions of the older generation in terms of wild edible usage and preparatory methods which can help alleviate the double burden of malnutrition among the population.
\end{abstract}

Keywords: Wild edible food systems; Food and nutrition security; Sansai

\section{Introduction}

The multidimensional issue of food security presents a global dilemma wherein the demand for food is expected to increase by up to $60 \%$ by the year 2050. Evaluating the causes of hunger, malnutrition and obesity requires an evolving understanding that the genetic base of most human caloric intake from plants is dangerously narrow. The current mainstream model of domestication, dominated by Mendelian pedigree breeding, has been maintained at the loss of horizontal, or broad, resistance to plant pests and diseases and a drastic reduction in the variety of plants eaten worldwide. Approximately $60 \%$ of the world's energy intake is heavily reliant on the three main staples (rice, maize, and wheat). Worldwide, the number of people suffering from obesity has finally surpassed the number of undernourished people from the year 2000 onward. The "double burden" of nutrition has started affecting many developing countries. These nations have to simultaneously cope with both the over- and undernourishment of their citizens. Since 2000, countries in all regions have experimented with numerous mechanisms to combat this trend, but the results have been inadequate. Malaysia is currently facing the most severe dietary crisis in East Asia, at a rate of approximately $50 \%$ of its populace being overweight or obese (Institute For Public Health, 2015). Research suggests that the disruption in work-life balance, household eating 
customs, and rapid shift away from indigenous diet are the main culprits, particularly in poor or lower-middle income households (Tee et al., 2018). Japan - a country with consistently good dietary outcomes for its relative level of development - has been the only country in Asia which has been able to withstand this contemporary threat.

\section{Literature Review}

\subsection{Wild Edibles In Maintaining Health and Well-Being}

As a tropical country, Malaysia is rich in biological diversity. Out of the 15000 species of vegetable plants available, only 300 species are indigenous to the country and have been used as food (Ministry of Agriculture, 1996). From the copious amount of research focused on traditional Malaysian leafy greens, results have proven that they not only possess higher nutrient content, but also beneficial antioxidants when compared to commercially cultivated vegetables (Asyira et al., 2016). It is sad to see that Malaysians have not accepted and embraced these underutilized plants, despite being healthier and viable alternatives due to their lower calorie content and glycaemic index in comparison to commercially cultivated crops.

Progressive flourishing food systems productively tap into an array of locally available food combinations and traditional food cultures. Japan has successfully kick-started various initiatives to revamp and reintroduce traditional vegetables into the diets of the urban population. This has a lot to do with the fact that the government has managed to preserve both their unique cultural and environmental aspects to the extent that fast food chains such as MOS Burger have also adapted to demands for regional and seasonal traditional produce. In line with their company's name, Mountain Ocean and Sun, they follow the underlying principle that environmental conservation should be tied in together in any food business, as it has a direct impact on health and well-being (Japan for Sustainability, 2006). From fast food to farmers' restaurants and farm stays, a lot has been done to ensure that tradi- tional vegetables are a vital part of their diets. However, the same cannot be said here in Malaysia. The inclusion of traditional vegetables, or 'ulam,' in the diets of the youth and urban populations is dwindling. Though there are many restaurants trying to feature some of these wild vegetables in their menu, the accessibility of these traditional vegetables is still restricted and confined to a very small and niche market.

As observed in Japan, biodiversity conservation is a key tool to dietary development matters as it is the base for their culinary traditions. The diversity observed in wild edibles and food supplies offers the heterogeneity that is needed to negate the deleterious effects brought about by commercial food to reduce hidden hunger issues and impart the nutrients, taste, and texture frequently absent from repetitive carbohydrate-rich diets typical of altered diets. Introducing these orphan species into urban diets would not only increase the opportunity to produce nutrient-rich food but simultaneously enhance the environmental capacity for future generations to supply themselves.

The romanticised view of local and traditional plant cultivation and preservation has not been fully adopted by flora rich countries due to the loss of cultural heritage, lack of knowledge, and nutritional data, thereby highlighting the socioeconomic consequences of modifying its status (Chweya \& Eyzaguirre, 1999).

\subsection{Rural Tourism}

A strong link between biodiversity, culture, and nutrition needs to be built in order for these plants to be successfully introduced into the diets of urban population as seen in Japan. The expression 'eco-' denotes house or habitat in Greek which was then further developed into the term 'turisimoecologico' by Hector Ceballos-Lascurain in 1981 which signifies ecotourism. Green tourism first started out in Europe in the early 1980s and was based on the European agricultural business to improve sustainability. This concept slowly extended its influence through Asia, particularly Japan whereby the Ministry of Agriculture, Forestry and Fisheries initiated a study group on green tourism with an aim to invest- 
Promoting underutilised food crops through tourism |313

igate the various agricultural activities available that could benefit both tourist and local inhabitants, as well as raising awareness of traditional culture and the natural beauty Japan has to offer (Bixia \& Zhenmian, 2013). The terms ecotourism, green tourism and rural tourism are used interchangeably in Japan which predominantly assimilates the wonders of nature, leisure activities, and agricultural whilst enabling the rural populace to earn a decent living (Kurisu, 2011).

\subsection{Women Empowerment}

The Chisan Chisho movement which promotes regionalism and the local production and utilization of the food kick started in the early 1990s due to the depreciation of agriculture and the rural populace (Taniguchi, 2002). Women who come from farming households mostly dominate the agriculture sector in Japan and are the backbone behind the Chisan Chisho movement. Hence it is structured particularly to empower women in local areas by teaching them how to preserve local/regional cuisine while learning to reduce sodium content and add more vitaminrich food ingredients. It is these women who often take up key roles in green tourism (Kimura \& Nishiyama, 2008; Nakamichi, 2010). With such projects, communities all around Japan have started to grow old-fashioned, native food ingredients instead of more profitable non-native varieties. In Malaysia, not much has been done to revitalize these crops and reintroduce them into the diet.

Located in the north of Honshu, Odate is at the north eastern corner of the Akita prefecture, well known for their apple and pear farms. The Akita prefecture has attempted to amplify the alluring charms of the area by reinventing links between regional dietary dishes and the beautiful mountains found in that area. The thing that makes Odate unique is that it merges both nature and food by practicing green tourism whereby farm stays and restaurants collaborate together to revive the consumption of traditional vegetables. Visitors get to learn about agricultural production and nature and eat at restaurants based on local food. Hence, the objective of this work was to showcase and learn the various initiat- ives taken by Japan and adapt them to a more localized concept and apply them here in Malaysia - particularly in regards to the role of women in preserving and safeguarding traditional vegetables in terms of farming and food preparation

\section{Materials and Methods}

\subsection{Site Selection}

Among all the various prefectures which offer farm stays, Odate was chosen as they not only had English speaking tours available for foreign guests, but were also recently awarded the IPRA Golden World Awards 2017 for the Akita Prefecture Tourism Campaign, also the 16th Oorai! Nippon Award and the Discover Mura no Takara by the Ministry of Agriculture, Forestry and Fisheries for being an exemplar village in regards to revitalizing local communities. Even though Akita is well known for its picturesque scenery, hot springs and many other sightseeing attractions, it has been difficult for the local travel industry and tourism agency to take advantage on the endless flocks of tourists to Japan, due to its location, as it is very far away from the bustling capital. As there isn't any local airport and public transportation can take up most of the travelling time, many tourists choose to bypass this location for other famous sightseeing sites. Besides that, Odate is also known for having a huge amount of snowfall during late autumn until early spring. To counteract and lure tourists, the Akita Inu Tourism joined forces to initiate a campaign by leveraging both the Akita dog breed and Japanese Idols.

In summary, some of the selection criteria in regards to the site were based on:

- Number of farm houses available

- Farming activities available

- Accessibility

- Role of local government in promoting green tourism

- Ease of communication

The study method was based on the phenomenological approach over a 5 day period, whereby

IJFS | October 2021 | Volume $10 \mid$ pages 311-321 
participatory observation and site visits to the various farms were undertaken by the researcher. Since language was a barrier, key informant interviewees were selected through Odate Cultural Activity Promotion Committee. Semi structured interviews were then conducted individually among 15 farm mothers identified by the committee and our host Mrs Ishigaki to gain a deeper understanding of the role the women play in ensuring good health among their families. Detailed information about the various types of 'sansai' used were asked, the incorporation of 'sansai' into the diets of local and the urban community, local delicacies and its relation to health and well-being, knowledge transmission among farm mothers and the various initiatives undertaken to ensure knowledge preservation. The questions were asked in English and then translated into Japanese by a translator working with the Odate Cultural Program Committee. Once the informants had answered, the translator would then interpret it back to English. Participant observation was also carried out during the researcher's stay to understand the interactions between human and plants when it comes to foraging. The researcher accompanied a few farm mothers in gathering 'sansai' in nearby areas, engaging them in conversation about the usage of these wild edibles as well as observe the foraging methods employed. The natural habitats of the plants was also recorded. During the five day stay, a different farm mother was assigned during each lunch and dinner to teach the researcher how these 'sansai's' are incorporated into their meals.

\section{Results and Discussion}

\section{$4.1 \quad$ Food}

As Odate is known for their local produce, most of the food featured in Mrs Ishigaki's place were vegetables. The cooking methods were the same throughout with the different farm mothers, though there were a few variations when it cames to pickling. As some 'sansai's' tend to be more fibrous in nature, they were usually boiled to help soften the texture. Others were pickled in rice wine vinegar and other seasonings (wasabi, soy, salt, sugar) or deep fried 'tempura' style. The best types of vegetables to utilize for making tempura include seasonal vegetables that are fresh as it is the main feature of the dish and the sauce is thought to be more of a garnish rather than a taste enhancer. On top of that, root vegetables are usually ideal as it can withstand higher temperatures and maintain its crispy texture due to the lack of moisture present. The Japanese also enjoy eating with their eye, hence colourful dishes were served during meals. The Kawaii culture does not only delight young children but also the elderly (Karasawa et al., 2011). Some of the highlights of the meals include kiritampo, which is an indigenous dish famous in the Akita prefecture and is usually eaten alongside a Japanese style hot pot with chicken stock also known as Kiritampo nabe. This dish is usually featured when visitors visit the locals and is made from freshly cooked rice that has been worked and pressed onto a skewer, glazed with sweet miso. It is then cooked on hot embers and can be eaten once toasted or can be broken into smaller pieces and placed in the hotpot (Japan National Tourism Organization, 2018). Akita is considered to be one of the top rice producing regions in Japan mainly due to its location (facing the Sea of Japan, the island of Tsuhima and also the Oou mountains) that contributes to the high night and day temperature differences. As it is considered to be a really traditional local food, various food companies have started producing kiritampo so that it can be enjoyed all the time.

Some of the other highlights included the Hinai Chicken which the Odate people are extremely proud of as it is a sought after delicacy. It contains high amounts of collagen and many other health benefits (Concierge, Akita). They usually consume the eggs raw, topped with soya sauce over steam rice. Another item which is unique and originates from Akita is tonburi. It is also considered as land caviar due to its greenish colour and is made from the Kochia Scoparia tree. The seeds are then dried, boiled, soaked and rubbed by hand to remove the outer layer. They can be served flavoured with soy (Casey, 2009). However, using it alongside yoghurt, will help mask the sourness of fresh yoghurt. 
Promoting underutilised food crops through tourism |315

Another delicacy that flourishes during early winter is the 'hata hata' also known as the fishing sailfin sandfish. The locals generally prefer the females with its egg pouches still intact and can be grilled, cooked or boiled. As with the vegetables, the 'hata hata' is also preserved by boiling it on soy or using salt and rice, so that it can be eaten all year round. The locals can only harvest the fish during winter months as it can only survive in the cold.

"We do not consume 'hata hata' in the summer. I could eat about 10-20 of this fishes daily. During winter, we have very limited protein options, this is what we usually eat. It has a very rich flavour and can be cooked, dried or pickled easily. The eggs are chewy and have a jelly like structure. It used to be very cheap, but now not so much anymore." Mrs Yamamoto, 67

Kanten (agar) was also used in one of the hotpot dishes. A quick brief history on its origin, explains that it is a jelly-like dish present at any wedding, funeral, or other ceremony held in Akita's southern region The locals use an extensive variety of ingredients to prepare it, is healthy and has a very long shelf life. Usually the locals prefer using new, exotic fruits and vegetables together with those preserved. In older times, every family would bring their own dish to ceremonies they attended, and kanten dishes were apparently highly valued for being easy to carry and eat.

\subsection{Role of Traditional Vegetables}

As the winters in Odate tend to be harsh and lengthy, most of the vegetables are pickled using harvested vegetables during summer and autumn. 'Gakko' is an example of a pickled dish made from daikon radish and is usually eaten as a snack while shovelling huge amounts of fallen snow. Other common preservation techniques include smoking and drying these radishes with seasoning.

Edible mountain vegetables also known as 'sansai' play a very significant role in the diets of the locals and are known as power food. Converting cultural to economic capital, these mountain vegetables are indispensable to local communities (Sutton et al., 2016). Many of these vegetables will ripen during spring and survive the long winters. As Odate experiences heavy and long snowfalls compared to the average Japanese city, this then allows the soil to thrive, thus producing nourishing vegetables. Due to the unfavourable conditions, the locals utilize many different techniques of cooking and preserving leafy greens.

"A lot of the vegetables featured in our diets are 'sansai' especially during spring, summer and autumn. We do get a few mountainous vegetables during winter which are perfect for tempura or the hot pot, but during this season, pickled vegetables are what we utilized more commonly." Mrs Tanaka, 68

"My husband and children prefer eating 'sansai' and crave for it during the long winter months. There is a richer flavour profile and it's more nutritious than the common vegetables in the market. The people here in Akita are mostly farmers, hence our diets revolve around vegetables. We have a seasonal calendar which showcases the various wild vegetables that thrive during different months." Mrs Sato, 73

As diverse as the Japanese landscape is, the same can be said about their cooking methods. Details on the time frame and the location for gathering these vegetables are posted on various websites and also published as calendars. One thing to note is that there are many different varieties of vegetables, and different villages have different types of 'sansai' cuisines. From once being recognized as famine food, these vegetables have been put on a pedestal in line with local traditions of emphasizing seasonality and to elicit memories of the archetypal hamlets found in Japan. However, not all mountain vegetables can be consumed, as some can be poisonous and harmful to health due

IJFS | October 2021 | Volume $10 \mid$ pages 311-321 
to various substances present in it.

Osawa argues in the preface to his mountain plant gathering guide that the subtle local flavours, wild origins and handpicked variety of mountain vegetables are perfectly suited to a Japanese palate sensitive to the complexities of food fragrance, sweetness, age, heat and moisture. Citing a final reason to the contemporary boom in mountain vegetables, Osawa explains as 'urbanization progresses and the population concentrates in cities, there is a strong trend of people seek the taste of their native place (Osawa, 2003).

The tastes of native places are a nostalgic reference to the foods that evoke warm human networks, local traditions and healthful environments associated with quintessential old villages in Japan. Mountain vegetables often also tend to be bitter in nature, and require a lot of prepreparation such as soaking or boiling to remove this overpowering flavour and make them more palatable (Makiko, 2011). The other method of cooking 'sansai' is to fry them tempura style. This tends to be preferred by young children.

The mountainous terrain of Japan has allowed local agricultural communities to uncover the hidden potential of natural resources, Satoyama is a term referred to mountain settlements that consist of mountain forests, paddy fields, farmlands and settlements governed by the rural populace (Chen \& Qiu, 2012), which was coined during the Edo period. In the past, locals relied heavily on these natural resources to ensure sustenance and biodiversity and just like the early settlers, most of the knowledge available was centered around the forest. Having its roots in environmental conservation, biodiversity preservation and accountable human governance, modern day environmentalists have tried to conjure Satoyama back into the hearts and mind of the people.

In Odate, foraging is still very much a lifestyle of the rural folk. Foraging for 'sansai' requires skills that are taught by the mothers and are refined over time. The amount harvested should also be taken into careful consideration. Usually foragers should pick about $1 / 3$ of each vegetable as overharvesting will lead to soil erosion and the loss of substantial gains. However, during early spring, many visitors from all parts of Japan come down to be part of this. In spite of rules and signs being posted, many of these inexperienced farmers ruin these plants, making them less available to produce a higher yield in the following seasons. Amateurs are often attracted to the various advertisements promoting the benefits of 'sansai' on radio and television, thus encouraging them to make the long trip down. The lack of knowledge among these urbanites are a major sustainability concern. To control the situation, farm mothers have started selling these 'sansai' in small cases, so as to decrease this from happening and preserving the continuity of production and survival of these plants. Also with the years of experience among farm mothers, they can recognize the ripened vegetables better compared to others that require a little bit more time, thus preventing further losses and destruction.

They have visitors not only from Japan on a regular basis, but also from America, Europe, Taiwan, China, Singapore and many other Asian countries. Even when locals stay with them, the farm mothers prefer to converse in their local Akita dialect. Though language might be a barrier, particularly with foreigners, the farm mothers choose to let their actions speak louder than their words by putting their heart and soul into making one feel comfortable and teaching everything they know. The older ladies hold bi-weekly gatherings during mid spring to late autumn to forage the local forest nearby. The mountain vegetables gathered are then brought back and prepared for their families.

\subsection{Role of women}

Mrs Ishigaki has been working as a farmer all her life and owns an apple farm. This was the same for all the women interviewed, who have been actively exposed to farming at an early age. Women do play a very active role in ensuring that cultural traditions are maintained. Fermented food was featured in every single meal and each family owns their own secret recipe, largely due to the time of the visit (very early spring). As Odate gets really cold during the winter, the people have to rely on fermented vegetables to get their daily dose of fibre, nutrients, and essential vitamins and minerals. Consumption 
Promoting underutilised food crops through tourism |317

of these fermented foods is one of the reasons attributed to the longevity of the population.

The farm mothers are representatives of farm developments working to revive the agriculture sector and promote local vegetables. Each activity is tailor made for their guests bearing in mind the different seasons. Some of the activities include harvesting apple, making 'Magge Wappa', a traditional bento box made from cedar, juicing apples, visiting Onsens, immersing in the natural beauty Odate has to offer.

One of their main target functions is to teach children the importance of preserving their lifestyle and culture. The farm mothers have started a theatre group that uses the Akita dialect to showcase their plays which revolve around the local culture, traditions and farming activities. During the cold winter months, young children are taught to pickle vegetables, make apple chips and traditional sweets, which encourages them to see the bigger picture of how produce are being transformed into other goods. Knowledge preservation is a key aspect when tailoring these activities as most farm mother's children are no longer pursuing farming.

\begin{abstract}
"We regularly have visits from primary school children both from the Akita region and from further prefectures as far as Okayama and Kochi. The farm mothers worked together on a puppet show not too long ago using the Akita dialect. A lot of the activities are created not only to promote fun, but for both children and adults to learn more about the heritage and culture involved in farming. My kids have all moved away, but these days, our grandchildren are slowly taking up agricultural based courses in the universities and are moving back to help us tend to the farms." Mrs Ito, 75 years old
\end{abstract}

As with most farming cities, their own kids have moved to urban, sprawling cities, leaving the aging population behind. Even with all the various activities they do, the farm mothers are still worried that they might not see young blood in the industry, though there has been a significant rise in interest over the past couple of years. The government is also slowly looking into ways to encourage the younger generation to move to farming towns and learn about agriculture.

Accessibility to health care is easy in Japan, but the rising community need is something that needs to be addressed. Academia is the first to jump on this bandwagon to help foster intergenerational discourse and gain deeper understanding on indigenous food culture and the direction its heading in the near future. The prevalence of non-communicable diseases is still relatively small in comparison to other developed countries. The government has looked into various measures and strategies to combat this issue. Blame shifting has occurred, whereby the female counterparts are deemed responsible for the ongoing ignominious failure. As more women have entered the workforce, the struggle between cooking and caring for the needs of their children and being a provider is difficult to maintain. The age-old customs of producing high quality local food have been severed. Domestication of crops has paved way for consumers to purchase these once seasonal produce all year long, hence allowing the younger generation to be oblivious of the difficulty in the past of sourcing it. However, the position of 'sansai' has been re-evaluated as many have started longing for the authentic Japanese 'mother's taste experience' where you can literally feel the tender loving care put in by these farm mothers when they painstakingly prepare these dishes, which can take hours at a time. Apart from that, generation $\mathrm{X}$ and millennials can start creating a sense of association and reconnect to their hometowns and it is a lot healthier. These farm mothers are willing to transmit and teach their ancestral knowledge for free and is a recurrent goal among the elderly. Though there has been a resurgence of interest, more still needs to be done to further these objectives.

Farm stays have been capitalizing on the recent yearning and desire of bona fide family recipes that have been passed on from one generation to the next. This goes a long way as many communities worldwide have lost their heritage, but it is different in Japan. Farm mothers in Odate have been working together to explore the various health benefits offered from 'sansai' and how

IJFS $\mid$ October 2021 | Volume $10 \mid$ pages 311-321 
to utilize them to their advantage. These recipes represent age-old insight that have been perfected by farm mothers to not only evoke a sense of familiarity but to showcase the depth of flavour in Japanese cuisine further reiterating the importance of women as preservers of knowledge and culture.

Women have also been the backbone of the farming and agriculture industry in Japan, though they have never been formally recognized for their contribution. A quick look at Mrs Ishigawa's role: she not only thinks of ways to promote her products but she can also be seen on the farm, making sure that the crops grow. After World War 2, the duality of lifestyle played by women in ensuring the well-being of the household whilst taking up opportunities in agricultural production and turning it into a stable income have become more prevalent, though they are still considered as farmer's wives and the men still play the central roles. The feminization of agriculture has grown exponentially and the number of women in farming has long surpassed men (Uemura, 2012). Although their roles are growing significantly, the lack of dominance and power in managing their own crops have limited their opportunities for capacity building and enhancing their status in life. As developed as Japan is, women empowerment is still lagging behind compared to other developing nations.

The women act as preservation agents in a family. This can be traced back to the past, whereby the women were in charge of domestic duties and the men were the sole bread winners of the family. Though times have changed, the Japanese still hold on to the paternalistic and authoritarian culture (Cheng et al., 2014). People who live in metropolitan cities tend to rely a lot more on convenience food. Many villages have started similar programmes that have been spearheaded by farm mothers, to rejuvenate their agricultural heritage. The term rejuvenation is needed to inject in some vitality into the aging population in Japan, and the decimation of the younger generation in pursuit of better lives away. Studies done by Yan et al. (2008), have highlighted the fine line between environmental protection and income generation when green tourism has been practised.

The farm mothers have started working together with an online marketeer to start marketing their produce to a wider audience. It is considered to be a success as their sales have increased by over $50 \%$ within the span of a year. Apart from that, the farm mothers launched various programmes targeted at youths and school children to start creating an interest in them, in hopes that they would continue to preserve their heritage. The farm mothers in Odate have just started the green tourism program targeted at foreigners for about 3 years now and farm stays for the locals for 6 years now. As most of them can only speak a few words, the usage of translation apps have come in handy, especially with tourists who are not well versed with English. English learning programmes have also being introduced by the Odate Cultural Activity Promotion Committee to help farm mothers familiarize themselves with basic English phrases to help ease communication.

The Cheerful Mother shop that works to connect agricultural villages with consumers through produce processing and direct selling, is an initiative between 69 different farm families and is spearheaded by women. Each family brings its own produce to sell that can range from flowers to 'sansai', pickled, fermented food, pre-packed meals alongside a café staffed with female chefs to recreate certain regional dishes. As this is considered a start-up initiative by the locals, it further emphasizes their roles in contributing financially to a family. A delivery system has also been set up targeted specifically at wild vegetables, with short announcements updated regularly on which vegetables are in season. They are picked up almost immediately after. Compared to other farmers' markets around the area, this shop is more specialised as all the farmers have been recognized as eco-farmers. Organic farming has not really picked up pace in Japan, yet food safety remains a priority for its citizens (Nakano, 2011). Eco farming is considered to be a step in the right direction for farmers to start transforming their farm lands to being completely organic. With this programme put in place, eco farmers are required to reduce their reliance on pesticide by $20 \%$, which will then be followed by $70 \%$ within the next 5 years, before they make the arduous shift to completely organic. Farmers are given 10 years to be certified as organic

IJFS | October 2021 | Volume $10 \mid$ pages 311-321 
farmers. Many of the uninhabited farm houses are now being turned into active farmlands to revive the dying farming and agri-business industry while actively promoting green tourism in line with governmental policies and local initiatives. They have started farming 'sansai', with these abandoned plots of lands, coupled with the easy maintenance of mountain vegetables as they thrive without any care or the use of insecticide, which provides a win-win situation for both parties. To top it off, the localization of growing 'sansai' can be seen as a boon to burgeoning cultivation.

\subsection{Adaptability}

One of the key features that these group of women possess is adaptability. As they cater to a diverse group of people yearly, these farm mothers do change their dishes from time to time to suit their guests. As there have been Westerners who have stayed there for longer periods of time, serving up authentic dishes can be a bit too difficult for them to stomach. As such, a few Westernized dishes like yoghurt and pasta are served, alongside Japanese seasoning.

\subsection{Marketing activities}

Exercise has also been vital in ensuring good and a long lasting life. Radiolethics is performed in the morning for 5 minutes together with music. Odate has been recognized as the best city in 2017 for providing a real authentic experience by JTB company which are the biggest tourism company in Japan. Currently, the committee are aiming for a much higher prize. With the money from the award, Odate Cultural Activity Promotion Committee have started a programme, targeted at foreigners to bring in a steady stream of foreigners who will not only be able to appreciate the diverse landscapes Odate has to offer but also the culture. The activities are tailor made to one's preference but is dependent on the various seasons.

\subsection{Linking Japanese initiatives and adapting it in Malaysia}

To start including wild edibles into the diets of Malaysians, more has to be done to involve the older generations as they are not only the main spokespersons of the community but also represent key knowledge holders in utilizing these wild edibles. The types of vegetables that can be used as sustenance, nutritive details and method of usage are held by them. As observed in Japan, many of the older generation play indispensable roles in creating new kinds of support networks in aiding the revitalizing of the enjoyment of healthy, social eating environments for children and older adults. Hence for Malaysians to compensate for hyperactive work-life circumstances for working class urban families and develop positive dietary habits for nutrition, a new found appreciation for the older generation and social eating customs needs to be inculcated.

\section{Conclusion}

Much can be said about the integration of sansei into modern day diets. The adaptability and marketing activities conducted by the cultural committee as well as government interventions have a lot to do with the success achieved. To preserve age-old traditions and to retain a form of cultural identity, these traditional plants should be the centre of a meal, therefore traditional cooking should also be documented. Promoting the usage of traditional plants can only be accomplished by emphasising their importance as well as supplementing further opportunities to boost their consumption. So in order for the urban class to shift away from the modern diet, a link between cultural identity and agricultural production should be renewed and restored.

\section{Acknowledgements}

I would also like to thank the Odate Cultural Activity Promotion Committee for hosting us and providing insight into their way of life. 


\section{References}

Asyira, S. A., Sarbini, S. N. S. R. \& Harah, Z. M. (2016). Mineral content of five indigenous leafy vegetable from bintulu market, sarawak malaysia. Journal of Medicinal Herbs and Ethnomedicine, 26-35.

Bixia, C. \& Zhenmian, Q. (2013). Green tourism in japan: Opportunities for a giahs pilot site. Journal of Resources and Ecology, 4(3), 285-292.

Casey, P. A. (2009). Plant guide for kochia (kochia scoparia). usda-natural resources conservation service, kansas plant materials center. Manhattan, Kansas.

Chen, B. \& Qiu, Z. (2012). Consumers' attitudes towards edible wild plants: A case study of noto peninsula, ishikawa prefecture, japan. International Journal of Forestry Research, 2012.

Cheng, B.-S., Boer, D., Chou, L.-F., Huang, M.-P., Yoneyama, S., Shim, D., Sun, J.-M., Lin, T.-T., Chou, W.-J. \& Tsai, C.-Y. (2014). Paternalistic leadership in four east asian societies: Generalizability and cultural differences of the triad model. Journal of Cross-cultural Psychology, 45(1, SI), 82-90. https://doi. org $/ 10.1177 / 0022022113490070$

Chweya, J. A. \& Eyzaguirre, P. B. (1999). The biodiversity of traditional leafy vegetables. University of Nairobi.

Institute For Public Health. (2015). Japan for sustainability. (2006). food as a bridge between humans and nature $(\operatorname{mos}$ food services, inc.). "toward a sustainable japan - corporations at work" article series article no. 35. jfs newsletter no.41 (january 2006). retrieved may 6, 2019, from.

Japan for Sustainability. (2006). Ood as a bridge between humans and nature $(\operatorname{mos}$ food services, inc.). "toward a sustainable japan - corporations at work" article series article no. 35. jfs newsletter no.41. http: //www.mos.co.jp/english/

Karasawa, M., Curhan, K. B., Markus, H. R., Kitayama, S. S., Love, G. D., Radler, B. T. \& Ryff, C. D. (2011). Cultural perspectives on aging and well-being: A comparison of japan and the united states. The International Journal of Aging and Human Development, 73(1), 73-98.

Kimura, A. H. \& Nishiyama, M. (2008). The chisan-chisho movement: Japanese local food movement and its challenges. $A g$ riculture and Human Values, 25(1), 4964.

Kurisu, Y. (2011). Review and future direction of green tourism in japan. Journal of Forest Economics, 57(1), 37-48.

Makiko, I. (2011). The unmistakable taste of a new season. springtime in japan means a selection of healthful bitter veg. $J a$ pan Times. https://www.japantimes. co .jp / life / 2011 / 04 / 22 / food / the unmistakable- taste- of - a- new - season / \#.XPn0YRYzbIU

Ministry of Agriculture. (1996). Malaysia: Country report to the fao. fao international technical conference on plant genetic resources. http://www.fao.org/fileadmin/ templates / agphome/documents / PGR/ SoW1/asia/MALAYSIA.pdf

Nakamichi, H. (2010). Chapter 3 the development of alternative production and consumption activities related to food safety and security and associated gender issues. From Community to Consumption: New and Classical Themes in Rural Sociological Research, 31-44.

Nakano, A. (2011). Organic agriculture in japan and perspectives on organic vegetable production in greenhouses. http:// www.fftc.agnet.org / library.php? func = view\&style=type\&id=20180523090115

Osawa, A. (2003). Yama no sachi: Riyu hyakka. Tokyo: Nobunkyo.

Sutton, P. C., Anderson, S. J., Costanza, R. \& Kubiszewski, I. (2016). The ecological economics of land degradation: Impacts on ecosystem service values. Ecological Economics, 129, 182-192. https://doi. org/10.1016/j.ecolecon.2016.06.016

Taniguchi, Y. (2002). Akita-ken ni okeru chisanchisho no torikumi. Tohoku Agricultural.

Tee, J. Y. H., Gan, W. Y., Tan, K.-A. \& Chin, Y. S. (2018). Obesity and unhealthy lifestyle associated with poor executive 
Promoting underutilised food crops through tourism |321

function among malaysian adolescents.

PloS one, 13(4).

Uemura, K. (2012). Reconstruction design toward sustainable societyindustrialization of scenery sector and new business of the female farmer. Journal of the Japan Society of Household Economics, 35, 143-149.

Yan, J., Wu, D. T. \& Xiao, M. (2008). Ecotourism: Balance between protection and development in agricultural heritage site - taking "traditional rice-fish agriculture" of qingtian county as an example. Rural Economy, 2, 74-77. 